\title{
Correction to: Identification of Crystalline Mineral Phases of Ornamental Latticed Jallies of Madras High Court Building, Tamil Nadu
}

M. Shivakumar, Thirumalini Selvaraj, Eleonora Odelli, and Rajan

\section{Correction to:}

Chapter "Identification of Crystalline Mineral Phases of Ornamental Latticed Jallies of Madras High Court Building, Tamil Nadu" in: J. Jayaprakash et al. (eds.), Advances in Construction Materials and Structures, Lecture Notes in Civil Engineering 111, https://doi.org/10.1007/978-981-15-9162-4_21

In the original version of the book, the misspelt co-author name "Eleonora Regattieri" has been changed to read as "Eleonora Odelli" in Chapter 21. The erratum chapter and the book have been updated with the change. 